\title{
As noções de usos do passado e de cultura histórica como instrumental analítico para a prática e a pesquisa no Ensino de História
}

The notions of past uses and historical culture as analytical tools for practice and research in history teaching

Célia Santana Silva*

Rocha, Helenice; Magalhães, Marcelo; Ribeiro, Jaime; Ciambarella, Alessandra (Org.)

Ensino de História: usos do passado, memória e mídia

Rio de Janeiro: Ed. FGV, 2014. 280p.

Os temas relacionados ao Ensino de História trazem reflexões que buscam enfrentar os desafios colocados atualmente pelas diversas demandas, temáticas e possibilidades para a história escolar. Qual história ensinar? Como equilibrar uma história que tem no seu projeto inicial um objetivo nacional com os interesses e expectativas dos sujeitos individuais e coletivos? São desafios que levam os pesquisadores a refletir sobre o uso social da história e suas interfaces entre o Ensino de História e a circulação social da história em diferentes esferas de produção, além de possibilitar considerações acerca dos usos do passado em variadas mídias. Isso significa também a ampliação de diálogos e olhares com e para a história pública, ou seja, as histórias que são produzidas para e além dos muros da escola.

O livro Ensino de História: usos do passado, memória e mídia é uma coletânea de artigos organizada em três partes, e resulta de uma iniciativa de pesquisadores que compõem e/ou dialogam com o Grupo de Pesquisa "Oficinas de História”. ${ }^{1}$ Organizado por Marcelo Magalhães, Helenice Rocha, Jayme Fernandes Ribeiro e Alessandra Ciambarella, o livro conta ainda com pesquisadores - Temístocles Cezar, Maria Lima, Angela de Castro Gomes, Aléxia

* Doutoranda em História, PPGH, Universidade do Estado de Santa Catarina (Udesc); Departamento de Ciências e Tecnologia, campus XVIII da Universidade do Estado da Bahia (Uneb). Eunápolis, BA, Brasil. celiasantanauneb@gmail.com 
Pádua Franco, Flávia Eloisa Caimi, Júnia Sales Pereira, Eucidio Pimenta Arruda e Rodrigo Bonaldo - vinculados a outras instituições universitárias, especialmente dos eixos Sul e Sudeste: Minas Gerais, Rio de Janeiro e Rio Grande do Sul, respectivamente (UFU, UFMG, UFF, UniRio, UFRGS e UPF). São pesquisadores que alinham suas perspectivas com o intuito de discutir as interfaces entre Ensino de História e a circulação social da história por meio das diferentes mídias e usos do passado, identificando a complexidade da relação passado-presente no fazer histórico. Eles convidam os leitores para algumas reflexões que repercutem desde o campo epistemológico da história até questões relacionadas ao enfrentamento que os historiadores estabelecem no contexto das discussões atuais sobre os usos do passado. Partindo de temas vigentes os/as autores/as que assinam os artigos do livro apresentam questões direcionadas para se pensar o Ensino de História como prática social e propõem discussões importantes para a formação do profissional de história que investiga o ensino e seus desdobramentos como objeto da pesquisa histórica.

Informa-se que o principal objetivo do livro é promover um "diálogo produtivo entre discussões da historiografia e do ensino de história, elaborando de forma reflexiva as fronteiras entre campos de pesquisa e reafirmando as relações constitutivas entre o mundo acadêmico e o escolar no ensino de história”. Para esses autores, devem-se ampliar as perspectivas do Ensino de História, considerado aqui como uma manifestação da história pública.

Dividido em três partes: "Diálogos entre a História e seu Ensino", "Usos do Passado: a história escolar" e "Usos do passado: a divulgação histórica", o livro apresenta 11 artigos que podem ser lidos individualmente, mas que também se complementam, pois tratam de temas em que o leitor pode exercitar interpretações diversas. Essa divisão se faz necessária para estabelecer diálogos, ampliar as discussões, e "superar os últimos cantões de encastelamento de uma história elitizada" no sentido de dar a conhecer a noção de história pública, que incorpore seus diversos públicos. A primeira parte apresenta alguns conceitos bastante atuais e mobilizados nas pesquisas sobre Ensino de História, tais como memória e mídia, regimes de historicidade e consciência histórica. $\mathrm{Na}$ segunda parte o enfoque recai sobre as estratégias didáticas no Ensino de História e seus desdobramentos, as mudanças que ocorreram como resultado das políticas de avaliação dos livros didáticos de história. Por último, propõe-se discutir como as mídias estão presentes e se relacionam com o Ensino de 
História, tornando-se textos ou resultantes de produtos culturais diversos. São partes que dialogam mesmo sendo independentes, e percebe-se que as noções apresentadas em cada parte do livro atravessam toda a obra.

Instigando professores, pesquisadores, estudantes e diversos públicos da história à busca por temas diferenciados e adensando discussões antes não iniciadas ou mesmo tratadas com superficialidade, o livro possibilita, com uma escrita firme e consistente nos vários artigos, novos olhares para o Ensino de História. Fazendo uso de uma bibliografia atual e diversificada, percebe-se uma disposição dinâmica e arrojada em apresentar um livro irmanado com as pesquisas históricas do tempo presente. Partindo dessa premissa, nota-se como estão ocorrendo alguns dos muitos usos do passado no espaço escolar, como as diversas memórias estão sendo mobilizadas e como as várias mídias se constituem como estratégias para esses usos do passado e são entendidas como instrumentos utilizados para o Ensino de História no ambiente escolar.

Os artigos que compõem a parte "Diálogos entre a História e seu Ensino" versam sobre os tempos históricos, os regimes de historicidade, mas também analisam como os elementos do passado se fazem presentes na sala de aula mediante produtos culturais disponíveis no mundo social. São textos que demonstram uma densidade teórica e uma boa incursão historiográfica empenhada em contextualizar e problematizar alguns conceitos a partir da cultura histórica.

O Ensino de História vem se renovando, e os historiadores mostram essa renovação por múltiplos olhares. $\mathrm{Na}$ abordagem de "O sentido de ensinar história nos regimes antigo e moderno de historicidade", Temístocles Cezar utiliza o conceito de regime de historicidade para apresentar as relações entre o passado, o presente e o futuro, destacando a necessidade de reflexões sobre o atual regime de historicidade no sentido de evidenciar o presente como fator determinante dentro da experiência histórica, configurando o que Hartog chama de presentismo. Helenice Rocha, em "A presença do passado na aula de História”, convida a observar como elementos do passado se fazem presentes na sala de aula, e como os professores fazem uso dos produtos culturais que tratam do passado e estão à disposição no mundo social.

Finalizando as discussões dessa primeira parte da coletânea, Maria Lima apresenta algumas reflexões que propiciam novos argumentos para uma discussão atual e pertinente no campo do Ensino de História, que é a 
aprendizagem histórica, explicada pela autora quando ela sinaliza que é preciso didatizar os conhecimentos, tornar ensinável o que os aprendizes trazem, perceber que antes de ser aluno é preciso ver um sujeito com aprendizagens e saberes. Apresentando diferentes autores que sob perspectivas epistemológicas diferentes sistematizaram os conceitos de consciência histórica, cultura histórica e educação histórica, bem como os seus usos, o artigo se torna uma nova referência para quem busca estudar e debater os sentidos do ensino da história. No texto, a autora tece considerações afirmando o mérito positivo das pesquisas e dos grupos analisados por ela, que vêm apresentando e desenvolvendo instrumentos para se pensar as possibilidades de reflexão sobre os jovens e crianças e suas relações com os saberes históricos. Certamente o sentido do Ensino de História não está dado, mas busca-se o melhor caminho a seguir. A consciência histórica e a educação histórica certamente acenam como uma possibilidade a ser seguida.

Na segunda parte, "Usos do passado: A História Escolar", o enfoque recai sobre a literatura escolar e as estratégias didáticas no Ensino de História e seus desdobramentos. As discussões versam sobre a instrução pública no Brasil republicano, livros didáticos e PNLD. São quatro artigos instigantes que atendem às novas demandas do Ensino de História. Ângela de Castro Gomes envereda por uma pesquisa repleta de possibilidades para pensar tanto culturas políticas quanto cultura escolar, apresentando resultados empíricos dos livros que foram utilizados na Instrução Pública no início do século XX em alguns estados do Brasil republicano, especificamente Minas Gerais e São Paulo. Analisando correspondências trocadas por Ana de Castro Osório com intelectuais, jornalistas e republicanos brasileiros, além de familiares, presenteia os leitores com informações preciosas sobre as redes de sociabilidade que ocorriam no Brasil República e também instiga-nos a perceber os meandros da formação de uma dada "identidade nacional", pois o material analisado em sua pesquisa versa sobre a nacionalidade exaltada no Brasil nos primeiros anos do século XX, bem como as relações luso-brasileira durante os anos 1910-1920. Flávia Eloisa Caimi traz encruzilhada, fronteiras e "sobrepeso de informações" e propõe uma discussão sobre as mudanças e demandas educativas e sociais a partir dos valores da geração Homo Zappiens. Mobiliza os conceitos de obesidade informativa ${ }^{2}$ e presentismo como chaves de leitura para entender como as sociedades contemporâneas adotam a tecnologia e desenvolvem novas 
estratégias de aprendizagem, de relacionamento e de convívio social. A autora analisa as possibilidades formativas implícitas à utilização de suportes de informação consideradas fontes para o estudo da história escolar, bem como suas contradições e seus limites, que desafiam professores e pesquisadores a uma mobilização constante sobre o aprender e ensinar história no tempo presente.

Na terceira e última parte do livro, "Usos do Passado: A Divulgação Histórica”, os quatro artigos trazem um panorama das discussões anteriores, com temáticas, que atravessam todo o livro. De modo geral, as mídias que apresentam a história com base em contextos, textos e produtos culturais são analisadas aqui como possibilidades de entender as problemáticas e os vários desafios lançados ao Ensino de História. O artigo de Alessandra Ciambarella, por exemplo, potencializa questões que permeiam cultura histórica, tempo presente e memória, quando traz à baila a complexa relação entre mídia audiovisual (cinema, TV) na elaboração e enunciação de discursos históricos, reconstruindo e reelaborando determinadas memórias, imagens e discursos em detrimento de outros. Ganham destaque o direito à memória, os usos do passado e as mídias que com seus diversos produtos sociais e culturais mobilizam o tempo presente e se impõem como possibilidades de fontes para o processo de aprendizagem histórica. Os textos sinalizam que as fronteiras entre escola e sociedade estão cada vez mais largas, pois questões como essa ultrapassam o universo escolar e são pautadas num debate público. Ou seja, os movimentos sociais e a escola dialogam e propõem novas perspectivas de interpretação para o Ensino de História e, assim, rompem com o eurocentrismo curricular que sempre norteou e orientou a sociedade brasileira.

O livro aqui resenhado contribui de forma significativa para o campo do Ensino de História, pois além de apresentar múltiplas investigações acerca dos usos do passado, considerando a cultura histórica como elemento articulador, possibilita perceber a circulação social da história e seu ensino em diferentes esferas de produção. Com questões centrais que problematizam a história pública no ambiente tanto escolar quanto acadêmico, a presente produção torna-se leitura obrigatória para um público que pensa e reflete sobre a forte presença dessa história nos diferentes espaços de produção do conhecimento. Certamente um livro com densidade teórica, questões instigantes e atuais, informações embasadas teoricamente se faz convidativo e garante uma rica 
leitura, que por certo permitirá engrossar os possíveis e irrecusáveis debates postos no campo do Ensino de História.

\section{NOTAS}

${ }^{1}$ Trata-se de grupo interinstitucional que reúne pesquisadores vinculados a diferentes instituições universitárias do Rio de Janeiro e de outros estados, os quais se dedicam a pesquisa na área de Ensino de História.

${ }^{2}$ Apropriação da expressão cunhada em: POZO, Juan Ignácio. Aprendizes e mestres: a nova cultura de aprendizagem. Porto Alegre: Artmed, 2002.

Resenha recebida em 20 de outubro de 2015. Aprovada em 12 de dezembro de 2015. 